\title{
Flora das cangas da Serra dos Carajás, Pará, Brasil: Santalaceae
}

\author{
Flora of the cangas of Serra dos Carajás, Pará, Brazil: Santalaceae
}

\section{Claudenir Simões Caires ${ }^{1}$}

\begin{abstract}
Resumo
Este trabalho apresenta descrições e comentários morfológicos e ecológicos sobre as espécies de Santalaceae registradas para as cangas da Serra dos Carajás no estado do Pará. Foram registrados dois gêneros e oito espécies: Dendrophthora warmingii, Phoradendron crassifolium, P. dipterum, P. mucronatum, $P$. obtusissimum, $P$. piperoides, $P$. quadrangulare, amplamente distribuídas pelas Américas Central e Sul, e $P$. tunaeforme registrada somente na Venezuela e Brasil.
\end{abstract}

Palavras-chave: Amazônia, ervas-de-passarinho, taxonomia, Viscaceae.

\begin{abstract}
This work presents descriptions, morphological and ecological comments on the species of Santalaceae recorded for the cangas of Serra dos Carajás in the Pará state. Were recorded two genera and eight species: Dendrophthora warmingii, Phoradendron crassifolium, P. dipterum, P. mucronatum, P. obtusissimum, $P$. piperoides, $P$. quadrangulare, widely distributed in Central and South America, and P. tunaeforme only registered in Venezuela and Brazil.
\end{abstract}

Key words: Amazonia, mistletoes, taxonomy, Viscaceae.

\section{Santalaceae}

Santalaceae s.l. inclui Amphorogynaceae, Cervantesiaceae, Comandraceae, Nanodeaceae, Thesiaceae e Viscaceae, compreendendo 44 gêneros e ca. de 1022 espécies, com distribuição tropical, subtropical a temperada (APG IV 2016; Nickrent et al. 2010). Na circunscrição da APG IV (2016) a família inclui ervas, arbustos e árvores hemiparasitas de raízes ou de órgãos aéreos, monoicas a dioicas. Folhas alternas ou opostas, perenes a caducas, expandidas a reduzidas a escamas. Inflorescências em monocásios, dicásios, espigas, racemos, panículas a umbelas, axilares a terminais, ou flores solitárias. Flores bissexuais a unissexuais, isostêmones, monoclamídeas a diclamídeas, 3-6-meras, as sépalas podem estar reduzidas a um calículo, dialipétalas a gamopétalas, corola campanulada a urceolada ou ausente, tricomas nas pétalas presentes ou ausentes, disco nectarífero presente ou ausente, ovário súpero a ínfero, sincárpico. Frutos drupáceos, bacáceos ou nozes. Essa circunscrição de Santalaceae foi adotada na Lista da Flora do Brasil (BFG 2015) e para a Flora das cangas de Carajás (Viana et al. 2016). No Brasil essa família é representada por oito gêneros e 68 espécies e, no Pará, foram registrados três gêneros e 25 espécies (BFG 2015). Nas cangas da Serra dos Carajás foram registrados Dendrophthora Eichler com uma espécie e Phoradendron Nutt. com sete espécies, todas conhecidas como ervas-de-passarinho ou enxertos-de-passarinho.

\section{Chave de identificação dos gêneros de Santalaceae das cangas da Serra dos Carajás}

1. Anteras uniloculares, 2-esporangiada 1. Dendrophthora

1'. Anteras biloculares, 4-esporangiada 2. Phoradendron

\footnotetext{
${ }^{1}$ Universidade Estadual do Sudoeste da Bahia, Depto. Ciências Naturais, Estrada do Bem Querer Km 4, 45031-900, Vitória da Conquista, BA, Brasil. cscaires@hotmail.com
} 


\section{Dendrophthora Eichler}

São plantas hemiparasitas de ramos aéreos, monoicas a dioicas, eretas a pendentes; $1-5$ pares de catafilos no entrenó basal do ramo lateral ou em todos os entrenós, livres ou formando bainha, persistentes a decíduos. Caule cilíndrico a quadrangular, em geral clorofilado. Folha carnosa a crassa, geralmente peciolada, venação acródroma ou eucamptódroma, raro reduzida a escama, decussada ou verticilada. Espiga terminal ou axilar, articulada, bissexual ou unissexual; 1 par de brácteas opostas cruzadas por artículo. Flores em 1-3 séries por bráctea no artículo, 3-meras, unissexuais; antera uniloculares, 2-esporangiadas. Fruto pomaceo-viscidio, liso a verrucoso, branco a amarelo, sépalas abertas eretas ou fechadas. Dendrophthora é muito similar a Phoradendron Nutt. sendo distinto apenas pelas anteras uniloculares (Caires 2003; Caires \& Proença 2005; Kuijt 2003, 2013b). Segundo Ashworth (2017) as análises filogenéticas preliminares indicam que esses gêneros não são monofiléticos. As estruturas vegetativas, profilos e catafilos, são importantes para a taxonomia de Dendrophthora e Phoradendron (Kuijt 2013a), assim como o padrão de venação e a seriação das flores nos artículos das espigas (Kuijt 2003), sendo muito utilizados nos trabalhos taxonômicos realizados no Brasil (Caires 2013; Caires \& Proença 2005; Dettke \& Waechter 2014; Rigon \& Cervi 2013; Vasconcelos et al. 2015). O gênero é exclusivamente Neotropical, distribuindose desde o México até a Bolívia, incluindo a região do Caribe, apresentando entre 115-120 espécies (Kuijt 2013b, 2015). Para o Brasil são registradas três espécies em quase todos os biomas brasileiros, exceto Pantanal (Arruda et al. 2012).

\subsection{Dendrophthora warmingii (Eichler) Kuijt,} Novon 13(1): 88. $2003 . \quad$ Figs. 1a-b; 2a-d

Hemiparasita monoica, verde-clara; catafilos basais, 1-2 pares em bainha bífida. Caule jovem elíptico a achatado-rômbico, adulto elíptico a cilíndrico, monopodial; entrenós 4-7,7 × 0,3-0,5 $\mathrm{cm}$, glabros; profilos decussados, $0,5 \mathrm{~mm}$ de compr. Folhas pecioladas; lâmina 5,4-7,5 × 3,1-4,8 cm, elíptica a obovada, carnosa, coriácea in sicco, glabra; ápice redondo, base atenuada; venação acródroma imperfeita suprabasal, 5 nervuras evidentes; pecíolo
$7-10 \times 1-1,5 \mathrm{~mm}$. Espigas $1-4$ por axila, $2-3 \times 0,3$ $\mathrm{cm}$, artículos 3-5, claviformes, com 2-10 flores bisseriadas. Flores estaminadas escassas, dispersas no artículo, $2 \mathrm{~mm}$ de diâm., 3-meras, sépalas 2/1 ou $1 / 2$, anteras uniloculares; flores pistiladas laterais ou apicais, 1,5 mm de diâm., 3-meras, com sépalas $1 / 2$ raro 2/1; estigma mamiloide. Frutos 3-4 × 2,5 $\mathrm{mm}$, ovoides, amarelos, sépalas abertas. Semente 2 $\times 1,5 \mathrm{~mm}$, elípticas, endosperma verde; embrião 1 $\mathrm{mm}$ de compr.

Material examinado: Parauapebas, Serra do Tarzan, 6019'14”S, 5005'58'”, 750 m, 15.XII.2007, fr., P.L. Viana et al. 3459 (BHCB).

Pode ser facilmente reconhecida dentre as espécies de Santalaceae de Carajás pelas anteras unilocualres e 2-esporangiadas. De acordo com Lira et al. (2017) essa espécie é encontrada sobre Vochysiaceae A. St.-Hil., no Pará, porém no material examinado da Serra dos Carajás, não há informações sobre o hospedeiro.

A espécie ocorre na Venezuela e Brasil, nas regiões Centro-Oeste, Nordeste, Norte e Sudeste (Caires \& Proença 2005). Em Carajás, foi registrada na Serra do Tarzan, em borda de mata com vegetação de canga.

\section{Phoradendron Nutt.}

Phoradendron são plantas hemiparasitas ou epiparasitas de ramos aéreos, monoicas a dioicas, eretas a pendentes; $1-5$ pares de catafilos no entrenó basal do ramo lateral ou em todos os entrenós, livres ou formando bainha, persistentes a decíduos. Caule cilíndrico a quadrangular, em geral clorofilado, raro cladódio achatado. Folha carnosa a crassa, geralmente peciolada, venação acródroma ou eucamptódroma, raro reduzida a escama. Espiga terminal ou axilar, articulada, bissexual ou unissexual; 1 par de brácteas opostas cruzadas por artículo. Flores em (1-)2-3(-5) séries por bráctea no artículo, (2-)3-4-meras, unissexuais; antera biloculares, 4-esporangiadas. Fruto pomaceo-viscidio, liso a verrucoso, branco a vermelho, sépalas abertas eretas ou fechadas. O gênero é exclusivamente Neotropical, distribuindo-se desde o sul dos EUA até a Argentina, apresentando entre 234-240 espécies (Kuijt 2003, 2015). Para o Brasil são registradas 55 espécies em todos os biomas brasileiros, sendo 18 endêmicas (Arruda et al. 2012).

\section{Chave de identificação das espécies de Phoradendron das cangas da Serra dos Carajás}

1. Folhas escamiformes; caules modificados em cladódios.......................2.7. Phoradendron tunaeforme

1'. Folhas não escamiformes; caules não modificados em cladódios ........................................................2

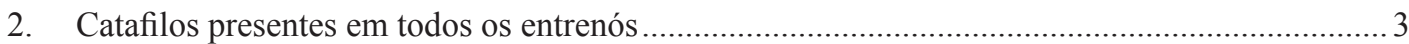


3. Entrenós com 1 par de catafilos estéreis; venação eucamptódroma

3'. Entrenós com vários pares de catafilos férteis; venação acródroma

2.5. Phoradendron piperoides

2.1. Phoradendron crassifolium

2'. Catafilos presentes apenas na base do primeiro entrenó dos ramos laterais

4. Caules não angulosos (elípticos a cilíndricos) .

2.4. Phoradendron obtusissimum

4'. Caules jovens angulosos (rômbicos, ancipitados a quadráticos)

5

5. Artículos da inflorescência com no máximo 6 flores; frutos verrucosos com sépalas eretas

2.3. Phoradendron mucronatum

5'. Artículos da inflorescência podendo apresentar mais de 6 flores; frutos lisos com sépalas fechadas.

6. Caules alados; artículos clavados; flores estaminadas apicais; epiparasita

2.2. Phoradendron dipterum

6'. Caules sem alas; artículos cilíndricos; flores estaminadas dispersas no artículo; não epiparasita 2.6. Phoradendron quadrangulare

2.1. Phoradendron crassifolium (Pohl ex DC.) Eichler, Fl. bras. 5(2): 125. 1868.

Figs. 1c-d; 2e-i

Hemiparasita monoica, verde-escura; catafilos intercalares férteis em todos os entrenós, (1-)2-4 pares em escama decídua; caule jovem e adulto cilíndricos, ramificados; entrenós 2,5-7 × 0,2-0,3 $\mathrm{cm}$, glabros; profilos decussados, $0,5 \mathrm{~mm}$, inteiros a franjados. Folhas pecioladas; lâmina (5-)7-11 $\times$ (2-)3,5-5,5 cm, verde-escura, lanceoladas, coriáceas in sicco, glabras, ápice agudo, base atenuada; venação acródroma imperfeita, nervuras 5 , espessas e salientes, evidentes na face abaxial; pecíolo $3-5 \times$ $1-1,5 \mathrm{~mm}$. Espigas 1-2 por catafilo e axila foliar, 2-3 $\times 0,2-0,3 \mathrm{~cm}$, artículos 3-5, cilíndricos, com 6-14 flores bisseriadas ou trisseriadas. Flores 1-1,2 mm diâm.; flores estaminadas apicais, 3-meras, sépalas 2/1; flores pistiladas laterais ou medianas, 3 -meras, com sépalas $1 / 2$ raro $2 / 1$; estigma mamiloide. Frutos 2,5-3 $\times 2 \mathrm{~mm}$, globoides a ovoides, pouco rugosos, maduros amarelados a alaranjado-pálidos, sépalas fechadas raro abertas; sementes $1,5 \times 1 \mathrm{~mm}$, elípticas, achatadas, endosperma verde; embrião 0,7 $\times 0,1 \mathrm{~mm}$, dicotiledôneo.

Material examinado: Serra dos Carajás, Serra do Norte, ca. $20 \mathrm{~km} \mathrm{~N}$ of AMZA Exploration Camp, $6^{\circ} \mathrm{S}, 50^{\circ} 15^{\prime} \mathrm{W}$, 18.X.1977, fl. e fr., C.C. Berg et al. 622 (MG).

Essa planta é facilmente distinta das demais espécies brasileiras por apresentar catafilos intercalares férteis e inflorescência, em geral, com mais de 3 flores por bráctea fértil. A coloração de suas folhas e ramos, assim como registrado em outras espécies, pode variar de verde-escura brilhante a verde-amarelada a depender da incidência solar (Caires \& Proença 2005; Dettke \& Waechter 2014).
A espécie tem ampla distribuição, ocorrendo desde a América Central até o Sul do Brasil, incluindo algumas ilhas do Caribe (Kuijt 2003). Ocorre por todo o Brasil registrada em todas as fitofisionomias (Arruda et al. 2012). Em Carajás, foi registrada em floresta de lianas na Serra Norte: N3. Essa espécie é considerada generalista quanto aos seus hospedeiros, florescendo e frutificando o ano inteiro (Caires \& Proença 2005, 2008; Dettke \& Waechter 2014; Rigon \& Cervi 2013).

2.2. Phoradendron dipterum Eichler, Fl. bras. 5(2): 109. 1868.

Fig. $2 \mathrm{j}-1$

Hemiparasita, epiparasita, monoica; catafilos na base do primeiro entrenó dos ramos laterais, 1 par em bainha; caule jovem quadrangular ou ancipitado, alado, quando adulto quadrangular alado a cilíndrico, ramificado; entrenós $2,5-6 \times 0,2-0,4$ $\mathrm{cm}$, glabros; profilos decussados, $1 \mathrm{~mm}$, franjados. Folhas pecioladas; lâminas 3-3,5 × 1,1-1,9 cm, elípticas, papiráceas in sicco, glabras, ápice obtuso, base longo-atenuada; venação acródroma imperfeita, nervuras 5-7, finas, igualmente visíveis em ambas as faces; pecíolo 3-8 $\times 1 \mathrm{~mm}$. Espigas 1-2 por axila, 4-4,5 × 0,2 cm, artículos 5-6 clavados, com 14-26(-30) flores trisseriadas, raro bisseriadas. Flores $0,6-0,8 \mathrm{~mm}$ diâm.; flores estaminadas 3 em arco apical, 3-meras, sépalas $2 / 1$ ou $1 / 2$; flores pistiladas laterais e medianas, (2-)3-meras, com sépalas $1 / 2$. Frutos $2-3 \times 1,5 \mathrm{~mm}$, globoides a ovoides, lisos, branco-róseos a branco-amarelados, sépalas fechadas; sementes $1-2 \times 0,7-1 \mathrm{~mm}$, elípticas raro ovais; embrião $0,5-0,8 \times 0,1-0,3 \mathrm{~mm}$. Material examinado: Serra dos Carajás, Serra do Norte, ca. $20 \mathrm{~km} \mathrm{~N}$ of AMZA Exploration Camp, $6^{\circ} \mathrm{S}, 50^{\circ} 15^{\prime} \mathrm{W}$, 18.X.1977, fl. e fr., C.C. Berg et al. 623 (MG). 

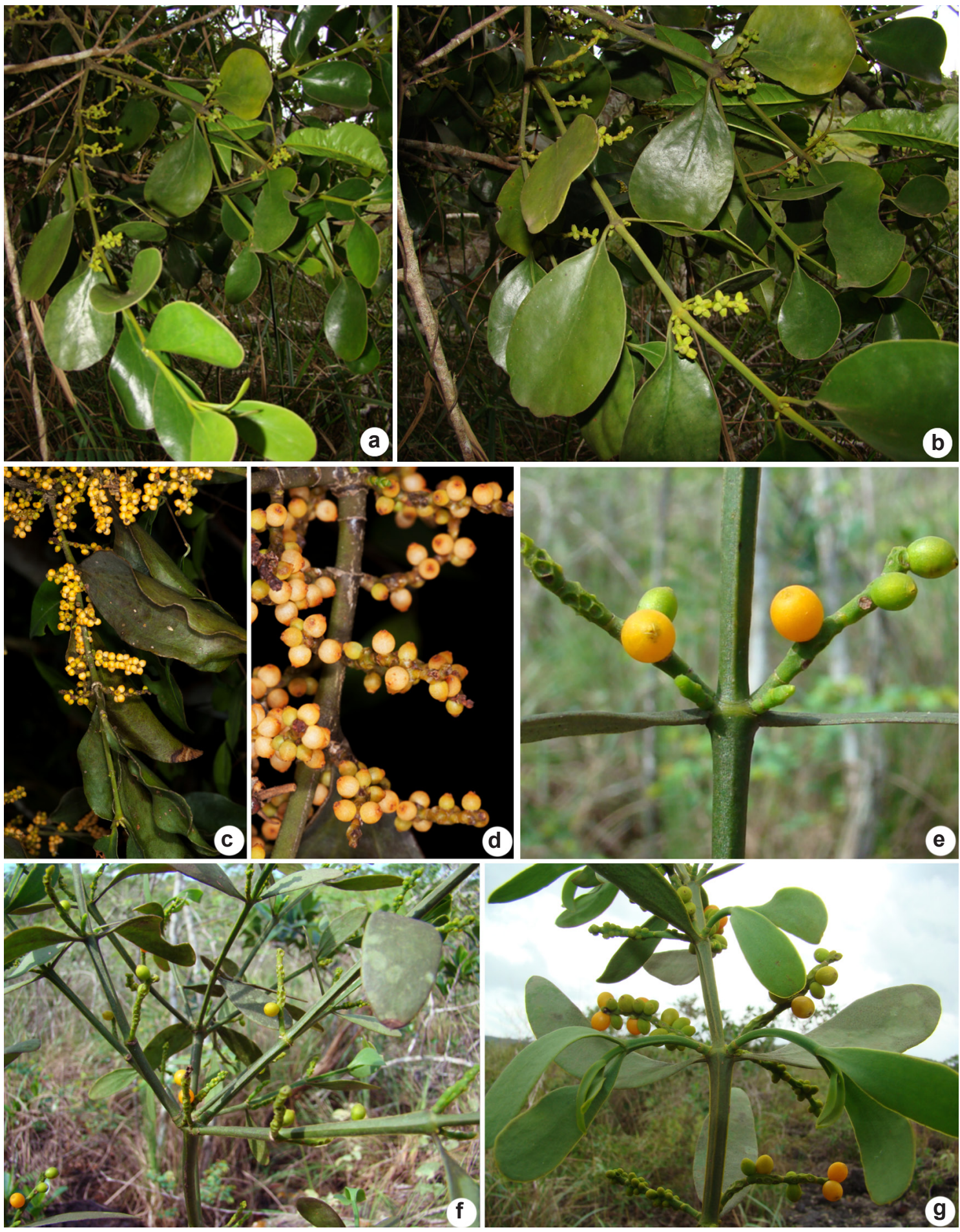

Figura 1 - a-b. Dendrophthora warmingii - a. hábito; b. inflorescência. c-d. Phoradendron crassifolium - c. hábito; d. inflorescências e frutos. e-g. Phoradendron quadrangulare - e. espigas e frutos; f. hábito; g. detalhes do caule, folhas e inflorescências com frutos. Fotos: a-b, e-g: Nara Mota; c-d: Climbiê Hall.

Figure 1 - a-b. Dendrophthora warmingii - a. habit; b. inflorescence. c-d. Phoradendron crassifolium - c. habit; d. inflorescences and fruits. e-g. Phoradendron quadrangulare - e. spikes and fruits; f. habit; g. details of the stem, leaves and inflorescences with fruits. Photos: a-b, e-g: Nara Mota; c-d: Climbiê Hall. 
Planta registrada apenas sobre outras espécies de Phoradendron, sendo considerada epiparasita obrigatória, florescendo e frutificando o ano inteiro (Caires \& Proença 2005, 2008; Dettke \& Waechter 2014; Rigon \& Cervi 2013). Caracterizada por apresentar caules alados, espigas trisseriadas com artículos claviformes e flores estaminadas efêmeras concentradas no ápice da série de flores num arco de 3-7 flores (Caires \& Proença 2005). O espécime aqui analisado apresentou espigas bisseriadas, sendo o único registro até o momento (Dettke \& Waechter 2014; Rigon \& Cervi 2013; Caires \& Proença 2005; Kuijt 2003).

Espécie registrada desde o México até o Sul do Brasil, incluindo Argentina e Caribe (Kuijt 2003). No Brasil, foi encontrada em quase todos os estados, ocorrendo em diferentes fitofisionomias (Arruda et al. 2012). Em Carajás, foi coletada em floresta de lianas parasitando $P$. crassifolium (Berg et al. 622) na Serra Norte: N3.

2.3. Phoradendron mucronatum (DC.) Krug \& Urb., Bot. Jahrb. Syst. 24(1): 34. 1897.

Fig. $2 m-p$

Hemiparasita, monoica; catafilos na base do primeiro entrenó dos ramos laterais, 1 par em bainha; caule jovem rombicamente achatado ou quadrangular, adulto quadrangular, cilíndrico raro elíptico, 1-3 ramificado, com nós grossos; entrenós 2,5-4,5 × 0,2-0,3 cm, glabros; profilos decussados, $0,9 \mathrm{~mm}$, inteiros raro franjados. Folhas pecioladas; lâminas $2-3 \times 1,8-2,5 \mathrm{~cm}$, obovadas, obovado-orbiculares, obovado-elípticas, papiráceas a coriáceas in sicco, glabras, ápice retuso a arredondado, base atenuada a longoatenuada; venação acródroma imperfeita, nervuras $3-5$, abaxialmente pouco visível, exceto a mediana que é saliente; pecíolo 3-5 × 1,5-2 mm. Espigas castanhas, $1-2(-3)$ por axila, $0,9-1,5 \times 0,2$ $\mathrm{cm}$, artículos 3-5 quadrangulares, com 6 flores bisseriadas. Flores $1 \mathrm{~mm}$ diâm.; flores estaminadas únicas apicais, 3(4)-meras, sépalas 2/1, 2/2; flores pistiladas laterais, 3(4)-meras, sépalas $1 / 2$, $2 / 2$. Frutos 2-3(-4) mm, globoides, verrucosos, verde-claros a verde-amarelados, sépalas eretas; sementes $2-2,1(-4) \times 1,8-2(-2,5)$ mm, elípticas ou orbiculares; embrião $0,9-1,5 \times 0,5 \mathrm{~mm}$.

Material examinado: Parauapebas [Marabá], Serra Norte, clareira à direita da estrada para o acampamento Azul, N1, 29.V.1982, fl. e fr., R. Secco et al. 385 (MG).

Espécie caracterizada pelos caules angulosos, folhas obovadas com três nervuras evidentes, em geral emarginadas e mucronadas, espigas bisseriadas com três flores por bráctea fértil e frutos verrucosos com sépalas eretas.

Espécie foi registrada para o México, América Central, Caribe, porção norte e sudeste da América do Sul (Kuijt 2003). No Brasil, foi encontrada em quase todos os estados, exceto Santa Catarina e Rio Grande do Sul (Dettke \& Waechter 2014). Em Carajás, foi coletada em Floresta de Terra Firme na Serra Norte: N1. Essa espécie é considerada generalista quanto aos seus hospedeiros, florescendo e frutificando o ano inteiro (Caires \& Proença 2005; 2008; Dettke \& Waechter 2014; Rigon \& Cervi 2013; Vasconcelos et al. 2015).

2.4. Phoradendron obtusissimum (Miq.) Eichler, Fl. bras. 5(2): 134m. $1868 . \quad$ Fig. 3a-e

Hemiparasita, monoica; catafilos na base do primeiro entrenó dos ramos laterais, 1 par na forma de bainha; caule jovem elíptico, caule adulto elíptico a cilíndrico verde-enegrecido in sicco; entrenós 4-6,5 × 0,2-0,6 cm, porção distal dilatada e ancipitada, nós intumescidos pela existência de 2-3 ramificações laterais por axila foliar; profilos decussados, $0,9 \mathrm{~mm}$, inteiros. Folha peciolada; lâminas 4-5 × 1,5-2,5 cm, obovada a obovado-elíptica, crassas in natura, cartácea in sicco, glabras, ápice redondo, base longo atenuada; venação acródroma imperfeita, 3-5 nervuras primárias finas evidentes, retículo inconspícuo; pecíolo 5-6 $\times 1 \mathrm{~mm}$. Espigas 1-4 por axila, 1,5-2,2 $\times 0,1 \mathrm{~cm}$, com 2-3 artículos férteis de $3-7 \mathrm{~mm}$ de compr., 1 artículo estéril de $2-6 \mathrm{~mm}$ de compr., 6-16(-22) flores por artículo, bisseriadas. Flores $1 \mathrm{~mm}$ de diâm., flores estaminadas, 3-4-meras, dispersas no artículo, em todo artículo ou em toda a inflorescência, perianto $2 / 1$ na apical, $1 / 2$ nas laterais; flores pistiladas escassas, dispersas no artículo, perianto $1 / 2$. Frutos $7 \times 3 \mathrm{~mm}$, elipsoides alongados, maduro alaranjado, sépalas eretas abertas; sementes não analisadas.

Material examinado: Parauapebas [Marabá], Serra Norte, Km 7 da estrada de Ferro Carajás, 12.VIII.1982, fl. e fr., U.N. Maciel et al. 798 (MG).

Espécie distinta por apresentar caules cilíndricos a elípticos com porção distal alargada, espigas delgadas, bisseriadas, em geral, com três flores por bráctea fértil e frutos elipsoides com sépalas eretas.

Espécie registrada na Costa Rica, Panamá e América do Sul (Kuijt 2003). Encontrada em quase todo o Brasil, exceto Santa Catarina e Rio Grande do Sul (Dettke \& Waechter 2014). Em 

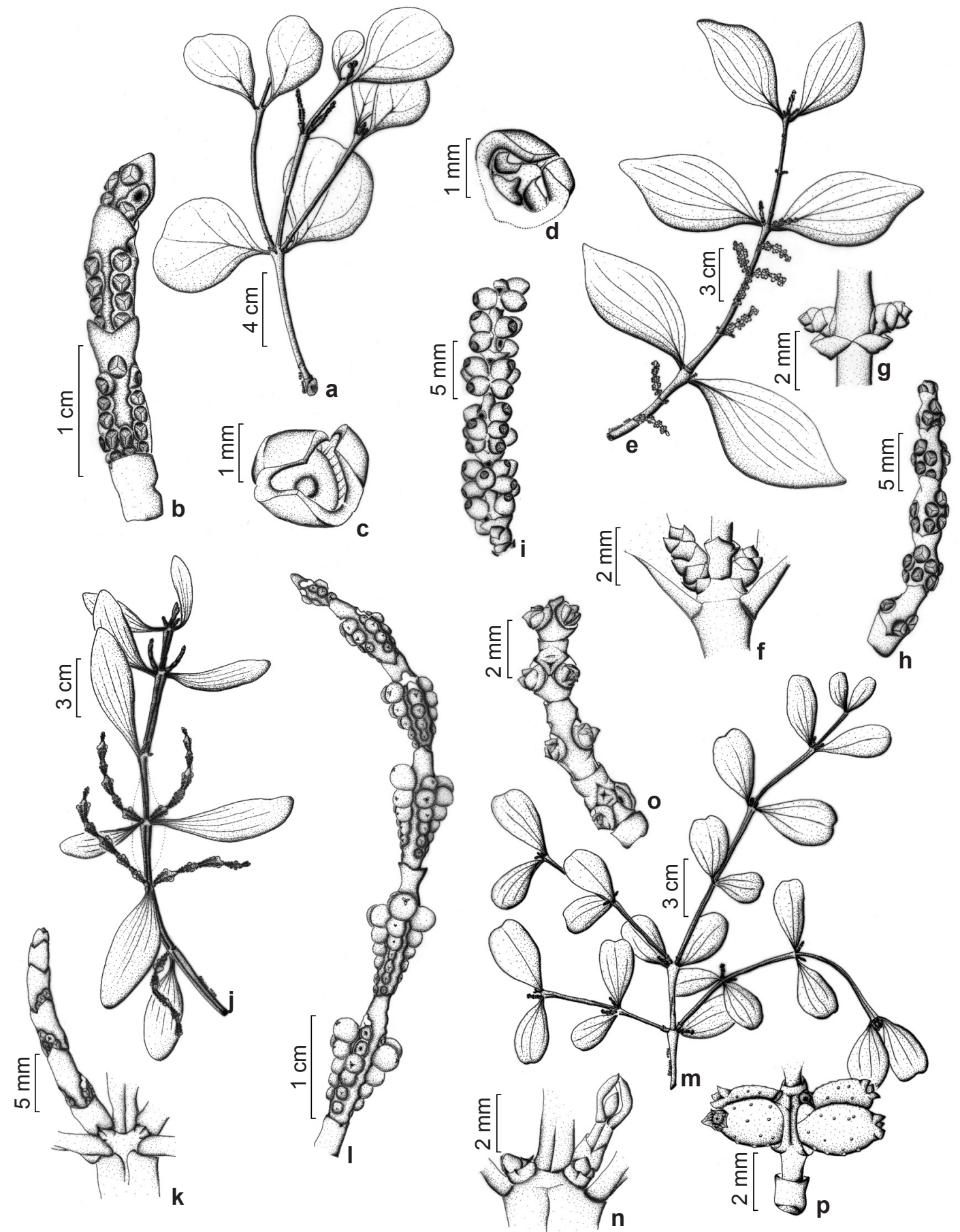

Figura 2 - a-d. Dendrophthora warmingii - a. hábito; b. espiga; c. flor feminina; d. flor masculina. e-i. Phoradendron crassifolium - e. hábito; f. catafilo basal e profilos das jovens inflorescências; g. catafilos intercalares férteis; h. inflorescência com flores; i. inflorescência com frutos. j-1. Phoradendron dipterum - j. hábito; k. profilos das jovens inflorescências; 1 . inflorescência com flores e frutos. m-p. Phoradendron mucronatum - m. hábito; $\mathrm{n}$. profilo e catafilo do ramo lateral; o. inflorescência com frutos jovens; p. frutos (reproduzida de Caires 2003).

Figure 2 - a-d. Dendrophthora warmingii - a. habit; b. spike; c. female flower; d. male flower. e-i. Phoradendron crassifolium - e. habit; f. basal cataphylls and prophylls of young inflorescences; g. fertile intercalary cataphylls; $h$. inflorescence with flowers; i. inflorescence with fruits. j-1. Phoradendron dipterum - j. habit; k. prophylls of young inflorescences; 1 . inflorescence with flowers and fruits. m-o. Phoradendron mucronatum - m. habit; $\mathrm{n}$. prophylls and cataphyll of lateral branch; o. inflorescence with young fruits; $\mathrm{p}$. fruits (reproduced from Caires 2003). 


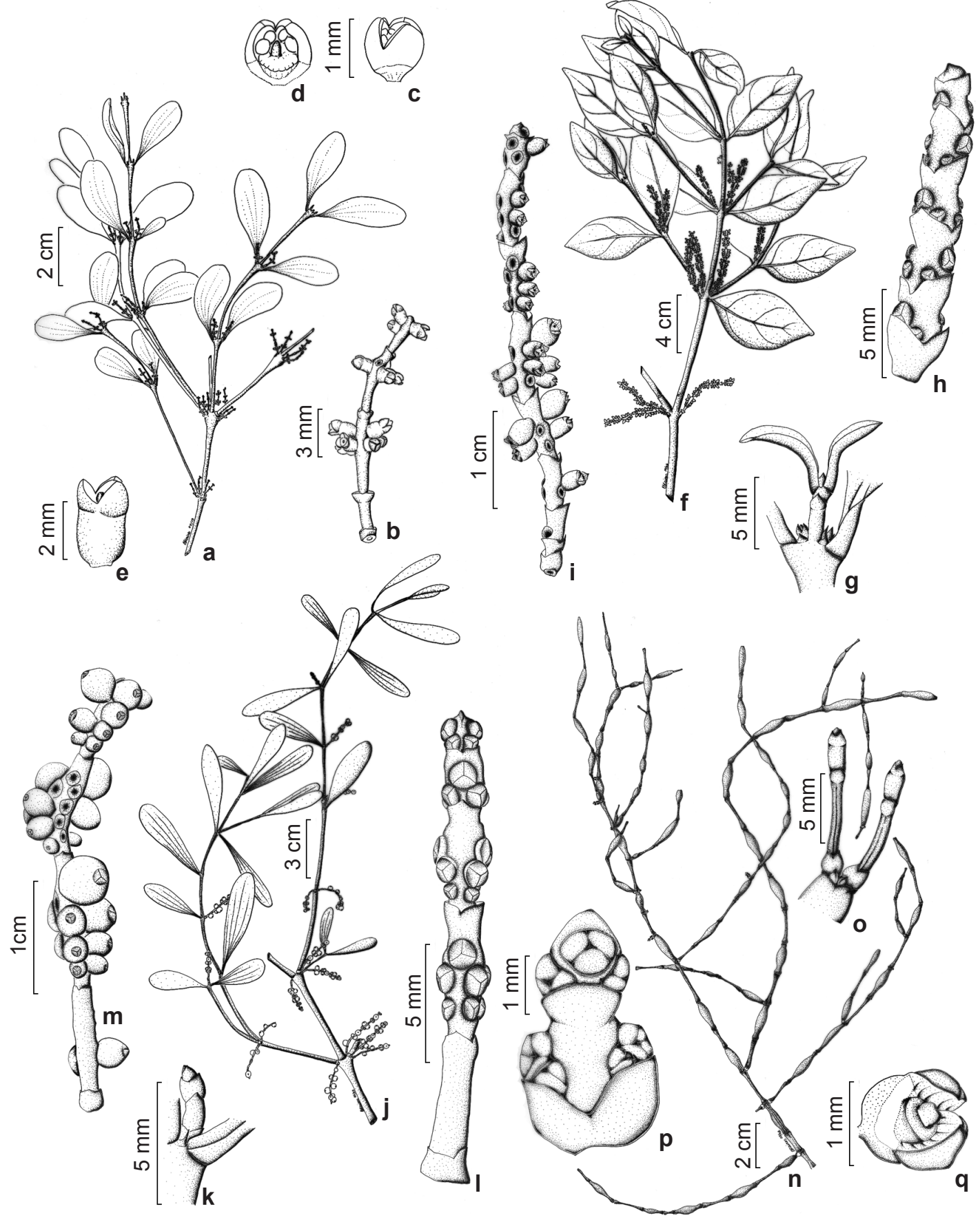

Figura 3 -a-e. Phoradendron obtusissimum - a. hábito; b. inflorescência com frutos jovens; c, d. flor masculina; e. fruto. f-i. Phoradendron piperoides - f. hábito; g. profilo da jovem inflorescência e catafilo do ramo apical; h. inflorescência com flores; i. inflorescência com frutos. j-m. Phoradendron quadrangulare - j. hábito; k. profilo da jovem inflorescência; 1. inflorescência com flores; m. inflorescência com frutos. n-q. Phoradendron tunaeforme - n. hábito; o. profilos, catafilos e folhas nos ramos jovens; p. inflorescência com flores; q. flor feminina (a-e. U.N. Maciel et al. 798; f-q. reproduzidas de Caires 2003).

Figure 3 - a-e. Phoradendron obtusissimum - a. habit; b. inflorescence with young fruits; $\mathrm{c}$, d. male flower; e. fruit. f-i. Phoradendron piperoides - $\mathrm{f}$. habit; g. prophyll of young inflorescence and cataphyll of stem apex; h. inflorescence with flowers; i. inflorescence with fruits. j-m. Phoradendron quadrangulare - j. habit; $\mathrm{k}$. prophyll of young inflorescence; 1 . inflorescence with flowers; $\mathrm{m}$. inflorecence with fruits. $\mathrm{n}$-q. Phoradendron tunaeforme $-\mathrm{n}$. habit; o. prophylls, cataphylls and leaves of young stems; p. inflorescence with flowers; q. female flower (a-e. U.N. Maciel et al. 798; f-q. reproduced from Caires 2003). 
Carajás, foi coletada em Floresta de Terra Firme com solo argiloso na Serra Norte. De acordo com as informações de hospedeiro a espécie pode ser considerada generalista, florescendo e frutificando o ano todo (Caires 2013; Dettke \& Waechter 2014; Rigon \& Cervi 2013).

2.5. Phoradendron piperoides (Kunth) Trel., Phoradendron 145. 1916. Fig. 3f-i

Hemiparasita monoica; catafilos estéreis em todos os entrenós, 1 par basal em bainha, segundo par escamiforme; caule jovem elíptico, adulto cilíndrico, 1-2(-4) ramificados; entrenós 3-5 × 0,2 $\mathrm{cm}$, glabros; profilos decussados, $0,5 \mathrm{~mm}$, inteiros. Folhas curto-pecioladas; lâminas 6-8 × 3-3,7 cm, lanceoladas a elípticas, coriáceas in sicco, glabras, ápice agudo, base breve-atenuada a obtusa; venação eucamptódroma, nervura mediana abaxialmente saliente, 2-3 pares de secundárias, abaxialmente mais visíveis; pecíolo 1,5-3 × 1,5 mm. Espigas 1-2 por axila, $3,5-4 \times 1,5 \mathrm{~cm}$, artículos férteis 5-6, cilíndricos, com (6-)10-18 flores por artículo, bisseriadas; 1-3 artículos estéreis. Flores $1 \mathrm{~mm}$ diâm., 3-meras, sépalas 2/1 nas flores apicais e $1 / 2$ nas laterais; flores estaminadas raras, dispersas no artículo; estigma mamiloide. Frutos $4 \times 2,5-3$ $\mathrm{mm}$, ovoides a globoides, lisos a pouco papilosos, amarelos a avermelhados, sépalas abertas; sementes $1,5 \times 1-1,5 \mathrm{~mm}$, elípticas raro orbiculares; embrião $0,8-1 \times 0,5 \mathrm{~mm}$.

Material examinado: Parauapebas [Marabá], Serra dos Carajás, estrada do estéril sul às proximidades da barragem, fl. e fr., O.C. Nascimento \& R.P. Bahia 1190 (MG).

Espécie caracterizada por um par de catafilos perenes e estéreis em todos os entrenós, folhas com venação eucamptódroma e nervura mediana evidente, espigas delgadas bisseriadas, em geral avermelhadas (Caires \& Proença 2005) a alaranjadas (Caires 2013).

Ocorre desde o México até o Sul do Brasil (Kuijt 2003). Encontrada em todos os estados da federação em diferentes fitofisionomias (Arruda et al. 2012). Em Carajás, foi registrada na Serra Sul. Espécie generalista encontrada sobre diversos hospedeiros, florescendo e frutificando o ano todo (Caires 2013; Caires \& Proença 2005, 2008; Dettke \& Waechter 2014; Rigon \& Cervi 2013; Vasconcelos et al. 2015).

2.6. Phoradendron quadrangulare (Kunth) Griseb., Fl. Brit. W.I. 711. 1864. Figs. 1e-g; 3j-m; 4a-b Hemiparasita monoica, verde-clara a verdeescura; catafilos na base do primeiro entrenó dos ramos laterais, 1 par em bainha, às vezes um segundo par escamiforme; caule jovem ancipitado a quadrangular com 4 linhas, adulto quadrangular a cilíndrico, 1-3 furcado; entrenós 1,5-6,5 $\times$ 0,2-0,4 cm, glabros; profilos decussados, 0,8 $\mathrm{mm}$, inteiros. Folhas pecioladas; lâminas 2-6 $\times$ 0,8-1,8 cm, verde-escuras, elípticas, oblongoelípticas a obovado-elípticas, verdes, papiráceas, cartáceas a coriáceas in sicco, glabras, ápice redondo, obtuso a agudo, com ou sem mucron, base atenuada; venação acródroma imperfeita, nervuras 3-5, finas igualmente visíveis; pecíolo 2-4 $\times 1 \mathrm{~mm}$. Espigas $1-3$ por axila, $1-3,5 \times 0,2$ $\mathrm{cm}$, verdes, artículos 3-5 férteis, 5-12 $\mathrm{mm}$ de compr., com (6-)10-18 flores bisseriadas, 1-2 artículos estéreis, 2-4 $\mathrm{mm}$ de compr., delgados. Flores 0,8-1 mm diâm., verde-amareladas, sépalas 2/1 nas flores apicais e 1/2 nas laterais; flores estaminadas apicais ou laterais, 3-meras; flores pistiladas apicais ou laterais, 3-meras. Frutos 3,5-4,5 × 2,5-3,5 mm, globoides, lisos, maduros alaranjados a vermelhos, sépalas abertas in natura, fechadas in sicco; sementes 1,5-2 × 1,5-2 mm, circulares; embrião $0,5 \times 0,1 \mathrm{~mm}$.

Material selecionado: Canaã dos Carajás, FLONA Carajás, Serra do Tarzan, no platô, 6¹9'45"S, $50^{\circ} 08^{\prime} 26^{\prime}$ 'W, 756 m, 01.IX.2015, fl. e fr., R.M. Harley et. al. 57332 (MG); Serra Sul, Corpo A, 6¹9'09'S, 50²6'44'W, 12.X.2008, fl. e fr., L.V. Costa et al. 596 (BHCB); Corpo B, 6²0'38'S, 4706'04'W, 12.X.2008, fl. e fr., L.V. Costa et al. 607 (BHCB); Corpo D, $6^{\circ} 23$ '57'S, 50²0'51'W, 764 m, 06.XII.2007, fl. e fr., N.F.O. Mota et al. 1072 (BHCB, MG). Parauapebas [Marabá], Serra Norte, arredores da estrada para N1, 17.V.1982, fl. e fr., R. Secco et al. 254 (MG); N2, 603'21'S, 50¹5'15'W, 756 m, 28.IV.2015, fl. e fr., $A$. Gil et. al. 458 (MG); N3, 14.III.1985, fl. e fr., R. Secco et al. 458 (MG); N4, mina piloto para exploração de ferro, 700-750 m, 14.III.1984, fl. e fr., A.S.L. da Silva et al. 1794 (MG).

Espécie bastante controversa quanto à sua circunscrição, devido ao grande polimorfismo de seus caules e folhas. Kuijt (2003) sinonimizou 37 nomes sob $P$. quadrangulare e mais recentemente Dettke \& Waechter (2015) sinonimizaram mais dois nomes. Em geral, a espécie é caracterizada por apresentar caules angulosos em algum período do desenvolvimento, catafilos somente no entrenó basal dos ramos laterais, espigas delgadas com flores bisseriadas e frutos globoides alaranjados a vermelhos com sépalas fechadas.

Possui ampla distribuição, ocorrendo desde o norte do México até o sul da América do Sul, incluindo o Caribe (Kuijt 2003). No Brasil, 
é registrada para quase todos os estados em diferentes fitofisionomias (Arruda et al. 2012). Em Carajás, foi coletada em área de canga arbustiva, com campo rupestre na Serra Norte: N1, N2, N3, N4, na Serra Sul: S11A, S11B, S11D e na Serra do Tarzan, parasitando Alchornea discolor Poepp. (Euphorbiaceae Juss.), Mimosa acutistipula (Mart.) Benth. (Fabaceae Lindl.), Callisthene microphylla Warm. (Vochysiaceae) e Licania Aubl. (Chrysobalanaceae R. Br.). É espécie considerada generalista, florescendo e frutificando o ano todo (Caires 2013; Caires \& Proença 2008; Dettke \& Waechter 2014; Vasconcelos et al. 2015).
2.7. Phoradendron tunaeforme (DC.) Eichler, Fl. bras. 5(2): 108. $1868 . \quad$ Figs. 3n-q; 4c-f

Hemiparasita monoica, verde-escura a verde-amarelada; catafilos na base do primeiro entrenó dos ramos laterais, único par em bainha bífida; caule jovem cladódio achatado, elíptico, adulto cladódio elíptico a cilíndrico, muito ramificado; entrenós $1-3,5 \times 0,2-0,4$ $\mathrm{cm}$, finamente papilados a glabros; profilos decussados, 0,8 mm, raramente franjados. Folhas escamiformes, 0,5-1 mm de compr. Espigas 1-2 por axila, $2-5 \times 1,5 \mathrm{~mm}$, artículos $1-2$ quadrados, com (2-)4-6 flores bisseriadas. Flores $0,8 \mathrm{~mm}$ diâm., verdes; flores estaminadas únicas apicais,
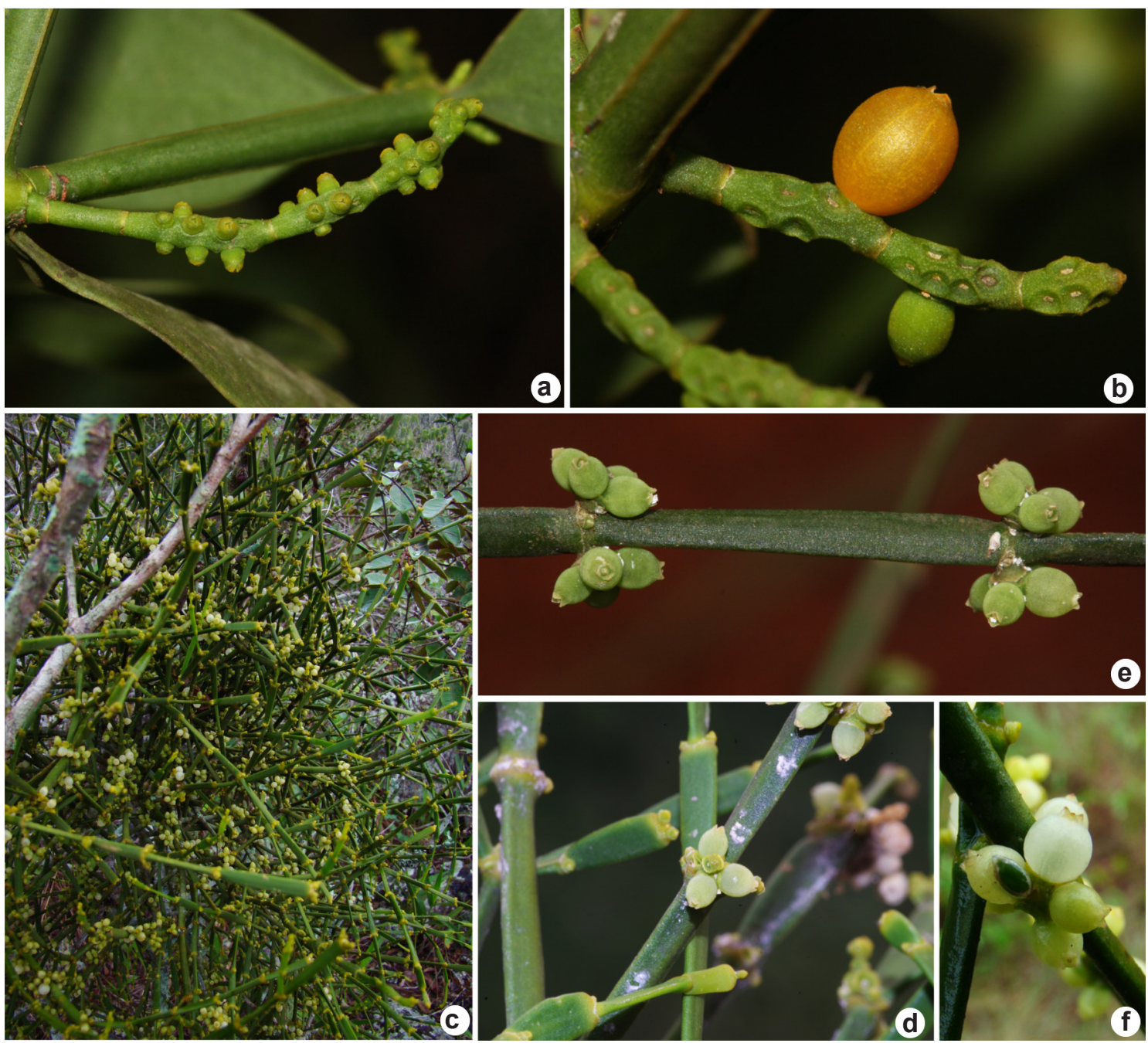

e

Figura 4 - a-b. Phoradendron quadrangulare - a. espiga; b. fruto maduro. c-f. Phoradendron tunaeforme - c. hábito; d. ramo jovem; e. entrenó e espigas; f. fruto maduro. Fotos: a-b, e: André Simões; c-d, f: Nara Mota.

Figure 4 - a-b. Phoradendron quadrangulare - a. spike; b. ripe fruit. c-f. Phoradendron tunaeforme - c. habit; d. young branch; e. internode and spikes; f. ripe fruit. Photos: a-b, e: André Simões; c-d, f: Nara Mota. 
3 -meras, sépalas $2 / 1$; flores pistiladas laterais, 3 -meras. Frutos 2-3,5 × 1,5-2,5 mm, ovoides, lisos a finamente rugosos, maduros brancos, sépalas eretas; semente 1,5-2 $\times 1 \mathrm{~mm}$, elipsoides, verde-escuro; embrião $0,8 \times 0,1 \mathrm{~mm}$.

Material selecionado: Canaã dos Carajás, FLONA Carajás, Serra Sul, Corpos A, B, C, 06 22'18"S, $50^{\circ} 23^{\prime} 05^{\prime}$ 'W, 727 m, 08.XII.2007, fl. e fr., N.F.O. Mota et al. 1119 (BHCB, MG); S11, 06 23'56'S, 50²1'52”'W, 650 m, 03.X.2009, fr, P.L. Viana et al. 4390 (BHCB); Corpo B, $06^{\circ} 22^{\prime} \mathrm{S}, 50^{\circ} 22^{\prime} \mathrm{W}, 800 \mathrm{~m}$, 18.II.2010, fl., A.J. Arruda et al. 197 (BHCB); S-11C, 06024'01'S, $50^{\circ} 23^{\prime} 18^{\prime \prime} \mathrm{W}, 753 \mathrm{~m}, 18 . I I I .2009$, fl. e fr., V.T. Giorni et al. 212 (BHCB, MG); S-11D, beira da estrada próximo à lagoa das macrófilas, $06^{\circ} 21^{\prime} 33^{\prime \prime} \mathrm{S}, 50^{\circ} 23^{\prime} 25^{\prime \prime} \mathrm{W}, 738 \mathrm{~m}$, 02.XII.2015, fl. e fr., A.S. Reis et al. 21 (MG).

Espécie distinta por apresentar caules em cladódio, folhas escamiformes, espigas com dois artículos de flores bisseriadas, com três flores por bráctea fértil. Por apresentar tais características e o hábito pendente pode, muitas vezes, ser confundida com Rhipsalis Gaertn. (Cactaceae Juss.) (Caires \& Proença 2005).

Segundo Kuijt (2003) essa espécie foi registrada apenas na Venezuela e no Brasil, nas regiões Centro-Oeste, Sudeste e Nordeste (BFG 2015). Em Carajás, foi coletada em Floresta Ombrófila Densa, canga arbustiva ou mata baixa de canga na Serra Sul: S11B, S11C, S11D. Há poucos registros sobre seus hospedeiros, mas os dados de Kuijt (2003) e Caires \& Proença (2008) indicam que a espécie seja generalista.

\section{Agradecimentos}

Agradeço à Dra. Ana Maria Giulietti, o convite; aos herbários do Museu Paraense Emílio Goeldi (MG), Mongoyós da Universidade Federal da Bahia - Campus Anísio Teixeira (HVC) e da Universidade Federal de Belo Horizonte (BHCB), o envio e recebimentos dos espécimes; à Dra. Andrea Karla Almeida dos Santos, o livre acesso aos espécimes e instalações físicas. Aos autores das fotos e à Nara Mota, a confecção das pranchas fotográficas. Esta é a publicação 21 da série técnica do Parasitic Plants Research Group.

\section{Referências}

APG IV (2016) An update of the Angiosperm Phylogeny Group classification for the orders and families of flowering plants: APG IV. Botanical Journal of the Linnean Society 181: 1-20.

Arruda R, Fadini RF, Carvalho LN, Del-Claro K, Mourão FA, Jacobi CM, Teodoro GS, van den Berg E, Caires CS, Dettke GA (2012) Ecology of Neotropical mistletoes: an important canopydwelling component of Brazilian ecosystems. Acta Botanica Brasilica 26: 264-274.

Ashworth VETM (2017) Revisiting phylogenetic relationships in Phoradendreae (Viscaceae): utility of the $\operatorname{trn} L-F$ region of chloroplast DNA and presence of a homoplasious inversion in the intergenic spacer. Botany 95: 247-258.

BFG - The Brazil Flora Group (2015) Growing knowledge: an overview of seed plant diversity in Brazil. Rodriguésia 66: 1085-1113.

Caires CS (2003) Viscaceae Batsch: Flora do Distrito Federal, Brasil. Dissertação de Mestrado. Universidade de Brasília, Brasília. 219 p.

Caires CS (2013) Viscaceae. In: Prata APN Amaral MCE, Farias MCV, Alves MV (orgs.) Flora de Sergipe. Vol. 1. Gráfica e Editora Triunfo, Aracajú. Pp. 550-555.

Caires CS \& Proença CEB (2005). Viscaceae. In: Cavalcanti TB, Ramos AE (orgs.) Flora do Distrito Federal, Brasil. Vol. 4. Embrapa Recursos Genéticos e Biotecnologia, Brasília. Pp. 43-76.

Caires CS, Proença CEB (2008) Levantamento preliminar dos hospedeiros de Dendrophthora e Phoradendron (Santalaceae) no Distrito Federal, Brasil. Heringeriana 2: 11-22.

Dettke GA, Waechter JL (2014) Estudo taxonômico das ervas-de-passarinho da Região Sul do Brasil: II. Viscaceae (Phoradendron). Rodriguésia 65: 955-985.

Gaviria VS, González F \& Mora NP (2017) Comparative inflorescence development in selected Andean Santalales. American Journal of Botany 104: 24-38.

Kuijt J (2003) Monograph of Phoradendron (Viscaceae). Systematic Botany Monographs 66: 1-643.

Kuijt J (2013a) Prophyll, calyculus, and perianth in Santalales. Blumea 57: 248-252.

Kuijt J (2013b) A brief taxonomic history of neotropical mistletoe genera, with a key to the genera. Blumea 58: 263-266.

Kuijt J (2015) Viscaceae. In: Kubitzki K (ed.) The families and genera of vascular plants. Vol. 12. Springer. Switzerland. Pp. 169-185.

Lira J, Caires CS \& Fadini RF (2017) Reaching the canopy on the ground: incidence of infection and host-use by mistletoes (Loranthaceae and Viscaceae) on trees felled for timber in Amazonian rainforests. Plant Ecology 218: 251-263.

Nickrent DL, Malécot V, Vidal-Russell R \& Der JP (2010) A revised classification of Santalales. Taxon 59: 538-558.

Polli A, Souza LA \& Almeida OJG (2016) Structural development of the fruits and seeds in three mistletoe species of Phoradendron (Visceae: Santalaceae). Rodriguésia 67: 649-659. 
Rigon J \& Cervi AC (2013) O gênero Phoradendron Nutt. (Viscaceae) no estado do Paraná, Brasil. Pesquisas Botânica 64: 15-38.

Vasconcelos GCL, Caires CS \& Melo JIM (2015) Flora da Paraíba, Brasil: Santalaceae R.Br. Iheringia (Série Botânica) 70: 203-215.
Viana PL, Mota NFO, Gil ASB, Salino A, Zappi DC, Harley RM, Ilkiu-Borges AL, Secco RS, Almeida TE, Watanabe MTC, Santos JUM, Trovó M, Maurity C \& Giulietti AM (2016) Flora das cangas da Serra dos Carajás, Pará, Brasil: história, área de estudos e metodologia. Rodriguésia 67(5 - Especial): 1107-1124.

\section{Lista de exsicatas}

Arruda AJ 197 (2.7), 443 (2.6). Berg CC 622 (2.1), 623 (2.2). Costa LV 592 (2.7), 596 (2.6), 607 (2.6), 925 (2.7). Gil A 458 (2.6). Giorni, V.T. 212 (2.7). Harley RM 57332 (2.6). Lima MPM 34 (2.6). Lopes CSA 04 (2.6). Maciel UN 798 (2.4). Mota NFO 1072 (2.6), 1119 (2.7). Nascimento OC 1190 (2.5). Reis AS 21 (2.7), 26 (2.6). Secco R 245 (2.6), 385 (2.3), 458 (2.6). Silva ASL 1794 (2.6). Viana PL 3459 (1.1), 4390 (2.7). 